\title{
Isobias curves in some detection tasks
}

\author{
TONY DUSOIR \\ Ulster Polytechnic, Newtownabbey, Northern Ireland
}

\begin{abstract}
Signal/noise ratio was varied in three tone-detection tasks while other conditions were held constant, generating 9 8-point and 12 12-point isobias plots. These plots were compared with the theoretical isobias curves associated with seven proposed bias measures. Each of the proposed measures covaried with signal/noise ratio in at least half of the data. For two of the plots, none of the measures was invariant. It is clear that different subjects respond quite differently to change in discriminability, and the implications of this for bias measurement are discussed.
\end{abstract}

Dusoir (1975) discussed the logic of choosing a bias measure for detection tasks, and complained that bias measures, unlike sensitivity measures, had proliferated with only the feeblest empirical justification: None of them had been shown to be invariant under change in such variables as signal/noise ratio, signal duration, or observation conditions. This paper looks at how the measures behave under change in just one of these variables, signal/noise $(\mathrm{S} / \mathrm{N})$ ratio.

\section{The Measures}

Suppose stimuli $s_{1}, s_{2}$ are presented in a series of independent trials with fixed probabilities $p\left(s_{1}\right)=$ $1-\gamma, p\left(s_{2}\right)=\gamma$, and $r_{1}, r_{2}$ are the corresponding responses. It is usual to write the hit probability $p\left(r_{2} \mid s_{2}\right)$ and the false-alarm probability $p\left(r_{2} \mid s_{1}\right)$ as functions of a sensitivity measure and a bias measure. Using $p$ for hit probability and $q$ for falsealarm probability, then, we have a sensitivity/bias parameterization of the form $q=f\left(\theta_{S}, \theta_{B}\right), p=g\left(\theta_{S}\right.$, $\theta_{\mathrm{B}}$ ), where $\theta_{\mathrm{S}}$ is the sensitivity measure and $\theta_{\mathrm{B}}$ the bias measure. If we keep $\theta_{\mathrm{B}}$ constant and vary $\theta_{\mathrm{S}}$, we trace out an isobias curve, that is, a set of points $q, p$ which share the same value of the bias measure but differ in sensitivity. We will use $\left[\theta_{\mathrm{B}}\right]$ to denote the curve family that keeps the bias measure $\theta_{\mathrm{B}}$ constant. What is at issue below is whether the various theoretical isobias curves in fact fit plots of hit and false-alarm rate as $\mathbf{S} / \mathbf{N}$ ratio alone changes. Equivalently, the issue is which of the bias measures in fact stay invariant under change in $\mathrm{S} / \mathrm{N}$ ratio.

Four of the measures are theory independent in the sense that they are defined just in terms of $q, p$, and $r$ :

This work was reported earlier as part of a D.Phil. thesis at the University of Oxford, 1980 . I would like to thank M. Coltheart, G. B. Henning, A. R. Jonckheere, and P. M. A. Rabbitt for their comments on the earlier version, and the editor and referees of this journal for their considerable help with this version. My mailing address is: School of Psychology, Ulster Polytechnic, Shore Road, Newtownabbey, County Antrim BT37 QB, Northern Ireland. $\left(1^{*}\right) \mathrm{q}$

$$
\left(2^{*}\right)(1-p) / q=C E R
$$

(3*) $p \gamma+q(1-\gamma)=p\left(r_{2}\right)$

(4*) $\mathrm{p} \gamma / \mathrm{q}(1-\gamma)=H$ (conditional falsealarm rate);

(conditional errorrate ratio);

(yes rate);

(absolute hit rate over absolute falsealarm rate).
Since the earlier paper (Dusoir, 1975) gives a full account of these and the other measures, and also some illustrative isobias curves, only a brief summary will be given here. Measure $1^{*}$ comes from normative statistical decision theory, and was argued for by Ingham (1970) and Treisman (1964). Measures $2^{*}$ and $3^{*}$ are of importance in connection with additive learning models: Some models of this family predict probability matching, $p\left(r_{2}\right)$ $=\gamma$, which is a special case of $\left(3^{*}\right)$, and others predict $\left(2^{*}\right)$ (see Dusoir, 1980, and Kornbrot, Donnelly, \& Galanter, 1981). Craig's (1976) model, and a special case of Ambler's (1976) model, also assume $\left[p\left(r_{2}\right)\right] .\left(4^{*}\right)$ comes from Healy and Jones (1973). Note that all these measures lead to linear isobias curves: That is, holding any one of them constant while sensitivity varies traces out a straight line of points $q, p$, whatever $y$ is. The slope of the line is infinite for $\left(1^{*}\right)$, negative for $\left(2^{*}\right)$ and $\left(3^{*}\right)$, and positive for $\left(4^{*}\right)$. The $q$ intercept is undefined for $\left(1^{*}\right)$, at $p=1$ for $\left(2^{*}\right)$, at $p=0$ for $\left(4^{*}\right)$, and may be free to vary or be undefined for $\left(3^{*}\right)$.

In contrast to these theory-independent approaches, another possibility is to assume underlying distributions, invariant under constant stimulus conditions, and then fix bias relative to these distributions. Numerous special cases of this scheme have been considered (Egan, 1975), largely in an attempt to fit empirical isosensitivity plots. The most popular distributional assumptions, perhaps, have been equal variance normal distributions, 
equal variance logistic distributions, or else unequal variance normal distributions. Within such a scheme, bias may be defined in terms of the behavior of the distributions at the observer's criterion or cutoff. That is, if the cumulative distributions are $F_{1}(x)$ given $s_{1}$, and $F_{2}(x)$ given $s_{2}$, with $q=F_{1}(c)$ and $p=F_{2}(c)$, then bias may be defined in terms of the behavior of the $F_{i}(x)$ at $x=c$. The main measures of this type are:

$$
\begin{gathered}
\log \left[F_{1}^{\prime}(c) / F_{2}^{\prime}(c)\right]=\log \beta, \\
1 / 2\left[F_{1}^{-1}(q)+F_{2}^{-1}(p)\right]=C, \\
F^{-1}(p) / F^{-1}(q) .
\end{gathered}
$$

Under the usual assumptions about the form of the distributions, all three lead to curvilinear isobias curves which go towards $q=0, p=1$. Measure $5^{*}$, like Measure $1^{*}$, came from normative decision theory; it has been used extensively in detection theory with a variety of assumed distributions (Egan, 1975; Green \& Swets, 1966). Measure 6*, with equal variance normal distributions, is Hardy and Legge's (1968) measure and, with logistic distributions, is Luce's (1963) $\log b$. Measure $7^{*}$ arises within the subjective Neyman-Pearson model of Curry, Nagel, and Gai (1977); their b parameter is related to Measure $7 *$ by

$$
(1+b) /(b-1)=\Phi^{-1}(p) / \Phi^{-1}(q) .
$$

where $\Phi(x)$ is the standard normal cumulative distribution function.

\section{The Tasks}

This paper reports individual-subject isobias plots, and some much more limited isosensitivity data, for three sinusoid-in-noise detection tasks: These differ in signal probability $(\gamma)$, payoff, feedback, and the manner in which discriminability is varied. In the first, signal level stays fixed and noise level varies randomly from trial to trial, no feedback is given, and bias is induced by asymmetric payoff, with $\gamma=.5$. The second is identical, except that noise level varies from block to block rather than trial to trial. In the third, noise level is constant and signal level is varied from block to block, trial-bytrial feedback is given, and bias is induced in separate conditions by $\gamma \neq .5$ with symmetric payoff, in one case, and by $\gamma=.5$ with asymmetric payoff, in the other.

Note that tasks in which discriminability varies from trial to trial raise a special issue. If noise level stays fixed and signal level varies, there are not separate sets of noise-alone trials from which separate estimates of false-alarm rate can be calculated for the various discriminability levels. Consequently, the subject is not free to choose an isobias function. This problem is avoided in the first of these experiments by giving two observation intervals at each trial, the first containing noise alone and the second containing noise and possibly a signal. Since, within each trial, noise level is the same for the two intervals, and signal level is fixed throughout, the subject can infer the current discriminability level from the first interval (perhaps with some error) and is free to alter bias accordingly.

For convenience, the details of all three tasks are given first, and then the behavior of Measures $1^{*}$ to $7^{*}$ is examined over the results as a whole.

\section{METHOD}

\section{Experiment 1}

In this experiment, four subjects each traced out three 5-point isosensitivity plots and one 8-point isobias plot in a no-feedback sinusoid-in-noise detection task in which discriminability varied randomly from trial to trial.

Procedure. The trial cycle was as follows. Continuous broadband noise at $50 \mathrm{~dB}$ SPL was present throughout the experiment. Two observation intervals were defined by .5 -sec increments in the loudness of the noise, separated by a 1-sec gap. Within a trial, the noise increments were always the same in magnitude, but between trials their magnitude varied through three levels (isosensitivity) or eight levels (isobias). The first interval always contained noise alone; the second contained a 1000 $\mathrm{Hz}$ sinusoid (switched on and off with the noise increment) with probability $\gamma=.5$. After the second noise increment there was a 5-sec response interval. In the isosensitivity sessions, subjects pressed one of six keys labeled, respectively: NO TONE, extremely confident; NO TONE, fairly confident; NO TONE, not at all confident; TONE PRESENT, not at all confident; TONE PRESENT, fairly confident; and TONE PRESENT, extremely confident. They were instructed, "Please try to use each of the six responses at least sometimes for each of the three levels of noise burst." In the isobias sessions, they responded with one of two keys marked NO TONE and TONE. There was no trial-by-trial feedback, but subjects were told the points scored at the end of each block of trials. A symmetric payoff matrix was used for the isosensitivity sessions (correct responses got 2 points; incorrect responses got -1 point); an asymmetric matrix was used for the isobias sessions (either $o_{11}=2, o_{21}=-1$, $o_{12}=-2, o_{22}=1$, where $o_{i j}$ is the payoff for $s_{i} r_{j}$, or else $o_{11}=1$, $\left.o_{21}=-2, o_{12}=-1, o_{22}=2\right)$. Five points were worth 1p (1 English penny) on completion of the experiment.

The signal when present was always at $67 \mathrm{~dB}$ SPL. For each subject individually, eight (or three) noise increments were chosen informally on the basis of the practice sessions so as to generate a good spread of discriminability. Since absolute discriminability is of no interest here, individual signal/noise measurements are not given; for the group as a whole, $E / N_{0}$, that is, the ratio of signal energy to noise power density, varied in the range 3 to 30 .

Signal and no signal were equiprobable; so, independently, were the various noise increment levels. There were no constraints equating the frequency of the trial types within blocks. Subjects were fully informed of the number of possible noise bursts and of the various presentation probabilities. In the initial practice sessions, they were shown several examples of the stimulus sequences and told to "note that there are no recurring patterns, and that the various types of trial occur about equally often, and that there may be quite long runs of the same type of trial." 
Sessions involved seven 50-trial blocks, separated by short breaks. Sessions were arranged freely to suit subjects, except that gaps of longer than 4 days were avoided. Any one session was devoted entirely either to the isosensitivity task or to the isobias task. In detail, the subjects' paths through the experiment were as follows (ISO = isobias, $\mathrm{ROC}=$ isosensitivity, $/ \mathrm{P}=$ practice, $/ \mathrm{A}=$ asymptotic): $\mathrm{S1}-6$ sessions $\mathrm{ROC} / \mathrm{P}, 10$ sessions ROC/A, 4 sessions ISO/P, 16 sessions ISO/A; $\mathrm{S} 2-2$ sessions ROC/P, 2 sessions ISO/P, 16 sessions ISO/A, 10 sessions ROC/ A; S3 -7 sessions $R O C / P, 10$ sessions $R O C / A, 2$ sessions $I S O / P$, 16 sessions ISO/A; and S4-2 sessions ROC/P, 2 sessions ISO/ $P, 16$ sessions ISO/A, 2 sessions ROC/P, 10 sessions ROC/A.

In the isobias sessions, the payoff favored yes responses for Subjects 1 and 4 and no responses for Subjects 2 and 3. The data to be reported are the last 300 trials of all the asymptotic sessions, giving an 8-point isobias curve with about 600 trials per point and three 5-point isosensitivity curves with about 1,000 trials per discriminability level.

In addition to the above, Subject 3 wanted to take part in further experiments, and was run for another 16 sessions under the other payoff scheme. Each pair of sessions used one of the same eight discriminability levels as in the main experiment, in freely random order.

Equipment. The $1000-\mathrm{Hz}$ sinusoid was generated by a phaseshift oscillator, gated by a solid-state gate using F.E.T.s, and mixed with broadband noise from a reverse-biased diode with frequencies above $15 \mathbf{k H z}$ filtered out. Four timers (Behavioural Research \& Development) were used to run the trial cycle. Noise and sinusoid were passed via a Ferrograph amplifier to Koss ESP9 earphones (binaural presentation). The experimenter switched manually between the noise-increment levels during the 5-sec response interval. Stimulus-response contingencies were recorded automatically on counters.

\section{Experiment 2}

This experiment varied discriminability between blocks, not between trials, but was otherwise similar to Experiment 1 . Four (different) subjects were run. There were two paths through the experiment: (1) 4 sessions ROC/P, 9 sessions ROC/A, 2 sessions ISO/P, 16 sessions ISO/A; and (2) 2 sessions ROC/P, 2 sessions ISO/P, 16 sessions ISO/A, 2 sessions ROC/P, 9 sessions ROC/A. Subjects 2 and 4 were assigned to path 1 , and Subjects 1 and 3 were assigned to path 2 . In the isobias conditions, payoff favored yes responses for Subjects 1 and 4 and no responses for Subjects 2 and 3. For each subject, discriminability levels were ordered randomly without constraint, two or three adjacent sessions being devoted to each level.

The asymptotic data to be presented therefore consist of an 8-point isobias plot with 600 trials per point and three 5-point isosensitivity plots with $\mathbf{9 0 0}$ trials per discriminability level.

\section{Experiment 3}

In this experiment, six subjects each traced out two 5-point isosensitivity plots under symmetric payoff and two 12-point isobias plots, one under asymmetric payoff with $\gamma=.5$ (/ASYM), the other under symmetric payoff, with $\gamma \neq .5$ (/SYM). The task was sinusoid-in-noise detection, with discriminability varied between blocks but not between trials.

Procedure. White quasi-Gaussian noise was continuous throughout the experiment at $79 \mathrm{~dB}$ SPL. The trial cycle was as follows. A central red warning light came on for $.2 \mathrm{sec}$. At its offset, on signal trials, the sinusoid was added for $.1 \mathrm{sec}$. There was then a 1.1-sec response interval, after which one of two white feedback lights came on for $1 \mathrm{sec}$ to indicate whether or not a signal had been present. At its offset, the warning light came on for the next trial.

Subjects responded using two response buttons (TONE, NO TONE) in the isobias sessions, and six response buttons, labeled as in the first two experiments, in the isosensitivity sessions. The side (left/right) of the TONE key(s) was freely random across subjects. For the ROC and ISO/ASYM conditions, $\gamma$ was .5. In the ISO/SYM condition, $\gamma$ was .25 for Subjects 3, 4 , and 5 (favoring no) and .75 for the others (favoring yes).

Payoff in points (10 points $=1$ English penny) was +1 for correct responses and -1 for incorrect responses in the ROC and ISO/SYM conditions. In the ISO/ASYM condition, Subjects 3,4 , and 5 had $o_{11}=2, o_{21}=-1, o_{12}=-2, o_{22}=1$, and the others had $o_{11}=1, o_{21}=-2, o_{12}=-1, o_{32}=2$. Subjects were told total points gained at the end of each block. Note that in this experiment no instructions were given in the isosensitivity conditions about using all the responses.

Each session contained six 200-trial blocks. The experiment always started with one session of practice at each of the ISO/ SYM and ISO/ASYM conditions. There then followed these three units in a freely random order across subjects: (1) 1 session ROC/low discriminability, 1 session ROC/high discriminability; (2) 1 session ISO/ASYM/P, 6 sessions ISO/ASYM/A; and (3) 1 session ISO/SYM/P, 6 sessions ISO/SYM/A.

Because there were no separate ROC practice sessions, the first 600 trials of each of the ROC sessions were discarded a priori, leaving 600 trials per isosensitivity plot. In the ISO/P sessions, discriminability was varied freely from block to block. In the 1SO/A sessions, discriminability was kept constant for three blocks at a time, and the first block was discarded a priori, leaving $\mathbf{4 0 0}$ trials per isobias point. Order of ROC and ISO discriminability levels was freely random over subjects; a different random order was used for the two ISO conditions. As in the first two experiments, discriminability levels were chosen informally for each subject individually on the basis of performance in the practice sessions, and levels were sometimes revised between the two ISO conditions. The range of $E / N_{0}$ for the group was 0 to 40 . All subjects took part in an $E / N_{0}=0$ condition, that is, a condition with no signal.

Equipment. The experiment was controlled by a programming network built up from IC transistor logic elements. All the time intervals were derived from a $12-\mathrm{kHz}$ crystal-controlled squarewave oscillator, which, after frequency division and analog filtering (distortion less than $.1 \%$ ), also provided the $1000-\mathrm{Hz}$ sinusoid, gated at positive-going zero crossing. Up to 16 sinusoid voltages could be preset using Beckmann 10-turn helipots (linearity and resettable accuracy about .05\%). A digital pseudorandom noise source was used, with a maximal sequence length of $2^{31}-1$ and a clock frequency of $500 \mathrm{kHz}$, giving a cycle time of $72 \mathrm{~min}$; spacing between spectral lines was $.0002 \mathrm{~Hz}$, and the $-.1-\mathrm{dB}$ point was at $\mathbf{4 0} \mathrm{kHz}$. The digital output was used to clock a ring counter, the 16 states of which could be patched many-one to the helipots to provide signal probabilities in multiples of $1 / 16$. The same noise with frequencies above $15 \mathrm{kHz}$ filtered out was mixed with the signal (when present) and passed through an audio amplifier to Koss ESP9 headphones. Stimulusresponse contingencies were recorded automatically on counters.

\section{RESULTS}

Any curve-fitting method that might be applied to these data would necessarily presuppose some specific model of trial-by-trial events; for example, the usual maximum likelihood methods for signaldetection data suppose independent trials, in which case both hit rate and false-alarm rate have a binomial distribution. Unfortunately, the independenttrials model is contradicted by the evidence (Green \& Swets, 1966), and no other model is well enough supported to stand in its place. Particular dependenttrials models may lead to very different distributions of hit and false-alarm rate, and the available 
curve-fitting procedures are not known to be generally insensitive to distributional assumptions. Consequently, some less assumption-bound approach is needed here. Fortunately, as pointed out in the earlier paper (Dusoir, 1975), the various proposals for bias measures lead to very different predictions, in the main. Consequently, given the fairly full isobias plots obtained here, it is possible to draw some strong conclusions by simple inspection of the data.

\section{Isosensitivity Data}

Isosensitivity hit and false-alarm rates for the first two experiments appear in Figures 1 and 2, along with the isobias data. Table 1 gives the isosensitivity data from Experiment 3. The main interest of the isosensitivity data is with respect to the proposed Bias Measures $5^{*}$ to $7^{*}$. Recall that Measures $1^{*}$ to $4^{*}$ are theory independent and so presume nothing about the shape of the isosensitivity function. Measures $5^{*}$ to $7^{*}$, in contrast, make distributional assumptions, which must be compatible with the isosensitivity data. The commonest assumptions, equal-variance normal or equal-variance logistic distributions, predict isosensitivity plots that are symmetric about the negative diagonal. In these data, as in many other published data, there is in fact some evidence of asymmetry. If we correlate $\hat{\mathrm{d}}^{\prime}$ (that is, $\Phi^{-1}(\hat{\mathrm{p}})-\Phi^{-1}(\hat{\mathrm{q}})$, where $\Phi(\mathrm{x})$ is the cumulative standard normal) with false-alarm rate $\hat{q}$, median Kendall's $\tau$ over the 24 cases of Experiments 1 and 2 is -0.40 , and is -0.33 over the 12 cases of Experiment 3. That is, $\hat{d}^{\prime}$ tends to fall as false-alarm rate increases. This is the kind of asymmetry commonly found (Green \& Swets, 1966) and often taken to be compatible with the assumption of unequal variance normal distributions.

It is obvious from Table 1 that dropping the explicit instruction to use all the responses turned out to have unfortunate, if illuminating, consequences: In some cases, there are too few points to characterize an isosensitivity curve properly. Questioned after the experiment, these subjects said that they felt unable to distinguish six degrees of confidence. This is illuminating just because it suggests that in some previously obtained rating scale data, from which attempts have been made to infer isobias curves, we may be looking at the joint effect of signal probability, payoff, and more or less informal pressure to use all the responses often enough to
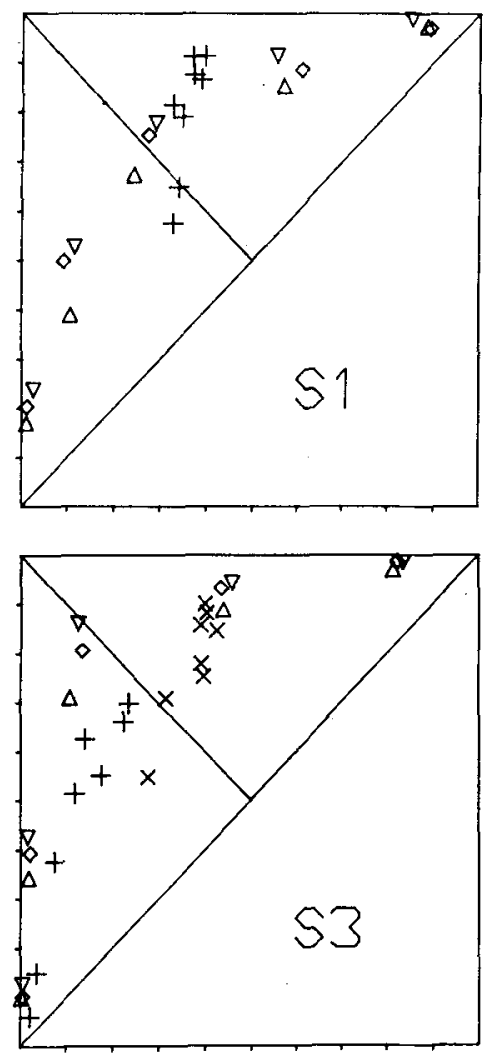
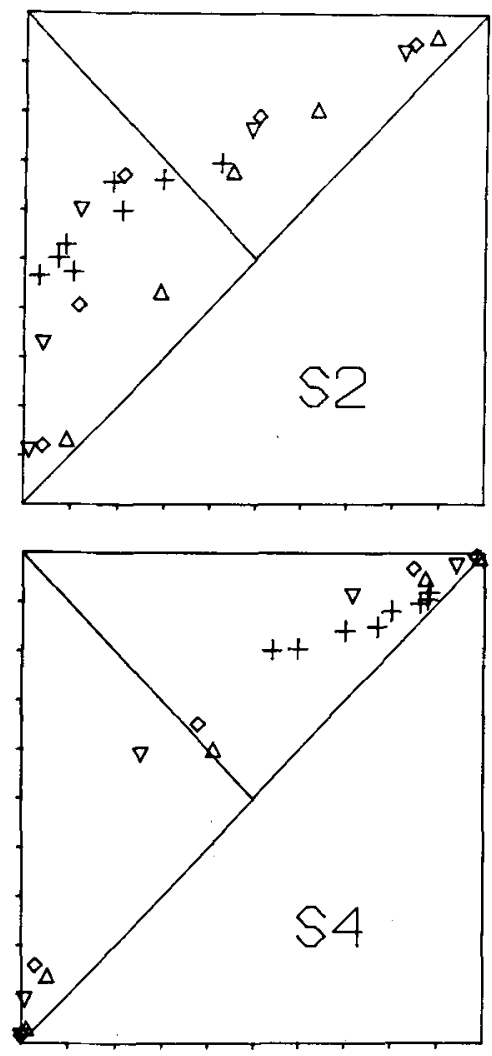

Figure 1. Isoblas and isosensitivity plots for Experiment 1. Vertical axis is p, horizontal is q; both axes are 0 to 1 linearty scaled. + , isobias (also $\times$ for $\mathbf{S 3}$ only); $\Delta$, isosensitivity/low discriminability; $\rangle$, isosensitivity/ medium discriminabillty; and $\nabla$, isosensitivity/high discriminability. There are about 600 trials per isobias point and about 1,000 trials per isosensidvity plot. 

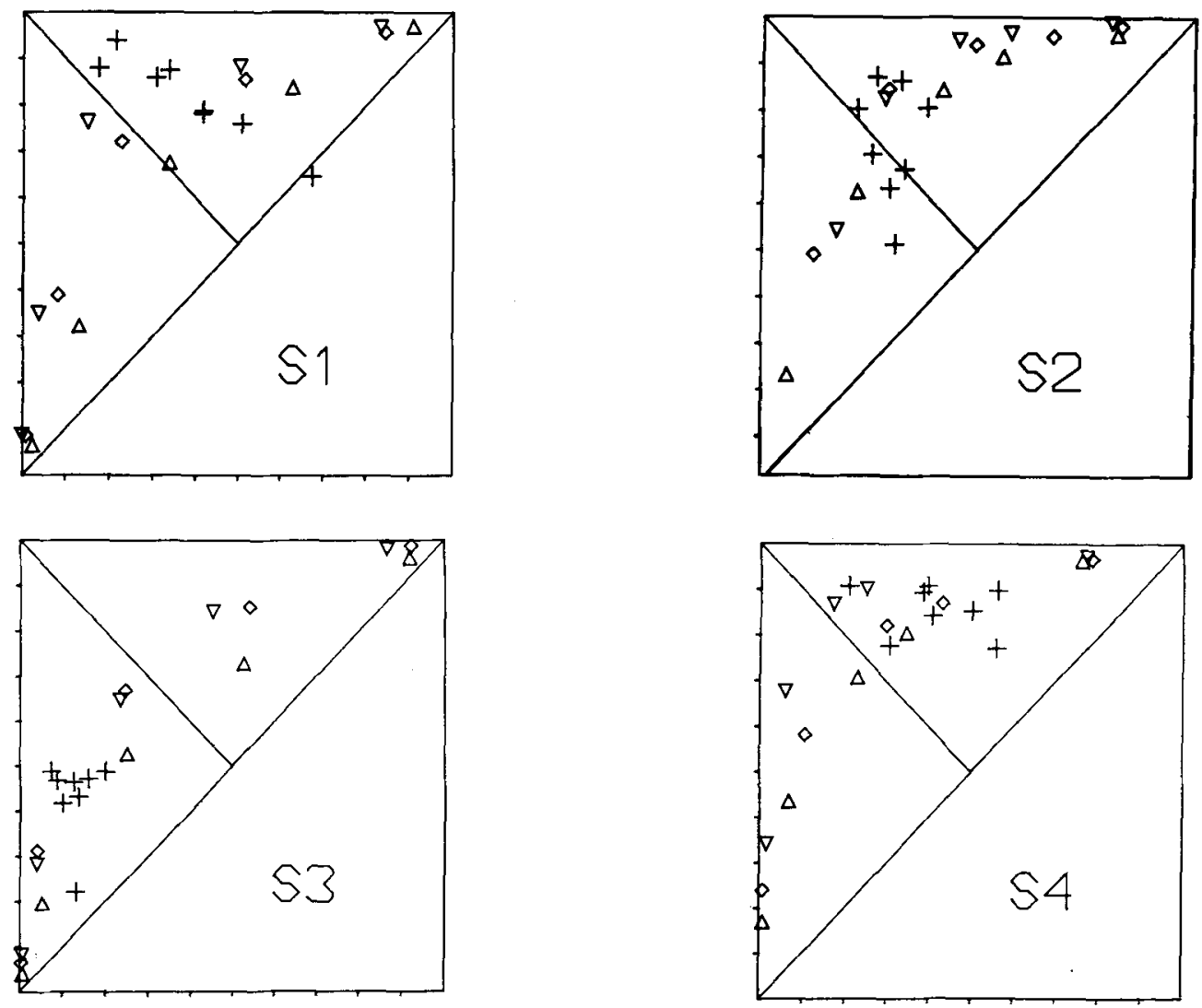

Figure 2. Isobias and isosensitivity plots for Experiment 2. Vertical axis is p, horizontal is q; both axes are 0 to 1 linearly scaled. Symbol convention as in Figure 1. There are about 600 trials per isobias point and about 900 trials per isosensitivity plot.

Table 1

Cumulated False-Alarm Rates ( $\hat{\mathbf{Q}})$ and Hit Rates ( $\hat{\mathbf{p}}$ ) for Low (L) and High (H) Discriminability (D) in the isosensitivity Conditions of Experiment 3, for Five Levels of Confidence $\left(r_{1}\right)$.

\begin{tabular}{|c|c|c|c|c|c|c|c|c|c|c|}
\hline \multirow[b]{2}{*}{ D } & \multicolumn{2}{|c|}{$\mathrm{r}_{2}$} & \multicolumn{2}{|c|}{$\mathbf{r}_{3}$} & \multicolumn{2}{|c|}{$r_{4}$} & \multicolumn{2}{|c|}{$\mathrm{r}_{5}$} & \multicolumn{2}{|c|}{$I_{6}$} \\
\hline & 4 & $\mathrm{p}$ & $\mathrm{q}$ & $\mathrm{p}$ & $\mathbf{q}$ & $\underline{p}$ & $\mathbf{q}$ & $\mathrm{p}$ & $\mathbf{q}$ & p \\
\hline \multicolumn{11}{|c|}{ Subject 1} \\
\hline $\begin{array}{l}\mathrm{L} \\
\mathrm{H}\end{array}$ & $\begin{array}{l}.996 \\
.930\end{array}$ & $\begin{array}{l}.994 \\
.987\end{array}$ & $\begin{array}{l}.942 \\
.719\end{array}$ & $\begin{array}{l}.941 \\
.965\end{array}$ & $\begin{array}{l}.620 \\
.232\end{array}$ & $\begin{array}{l}.732 \\
.873\end{array}$ & $\begin{array}{l}.290 \\
.081\end{array}$ & $\begin{array}{l}.380 \\
.498\end{array}$ & $\begin{array}{l}.065 \\
.018\end{array}$ & $\begin{array}{l}.074 \\
.168\end{array}$ \\
\hline \multicolumn{11}{|c|}{ Subject 2} \\
\hline $\begin{array}{l}\mathrm{L} \\
\mathrm{H}\end{array}$ & $\begin{array}{l}.977 \\
.921\end{array}$ & $\begin{array}{l}1 \\
1\end{array}$ & $\begin{array}{l}.690 \\
.100\end{array}$ & $\begin{array}{l}.888 \\
.886\end{array}$ & $\begin{array}{l}.167 \\
.085\end{array}$ & $\begin{array}{l}.687 \\
.878\end{array}$ & $\begin{array}{l}.075 \\
.085\end{array}$ & $\begin{array}{l}.364 \\
.871\end{array}$ & $\begin{array}{l}.003 \\
.000\end{array}$ & $\begin{array}{l}.061 \\
.236\end{array}$ \\
\hline \multicolumn{11}{|c|}{ Subject 3} \\
\hline $\begin{array}{l}\mathrm{L} \\
\mathrm{H}\end{array}$ & $\begin{array}{l}.720 \\
.522\end{array}$ & $\begin{array}{l}.794 \\
.860\end{array}$ & $\begin{array}{l}.301 \\
.334\end{array}$ & $\begin{array}{l}.511 \\
.777\end{array}$ & $\begin{array}{l}.239 \\
.308\end{array}$ & $\begin{array}{l}.476 \\
.771\end{array}$ & $\begin{array}{l}.232 \\
.301\end{array}$ & $\begin{array}{l}.453 \\
.728\end{array}$ & $\begin{array}{l}.166 \\
.291\end{array}$ & $\begin{array}{l}.341 \\
.664\end{array}$ \\
\hline \multicolumn{11}{|c|}{ Subject 4} \\
\hline $\begin{array}{l}\mathrm{L} \\
\mathrm{H}\end{array}$ & $\begin{array}{l}.914 \\
.114\end{array}$ & $\begin{array}{l}.961 \\
.945\end{array}$ & $\begin{array}{l}.340 \\
.086 *\end{array}$ & $\begin{array}{l}.730 \\
.945 *\end{array}$ & $\begin{array}{l}.291 \\
.086 *\end{array}$ & $\begin{array}{l}.699 \\
.945^{*}\end{array}$ & $\begin{array}{l}.266 \\
.086^{*}\end{array}$ & $\begin{array}{l}.666 \\
.945^{*}\end{array}$ & $\begin{array}{l}.119 \\
.069\end{array}$ & $\begin{array}{l}.449 \\
.939\end{array}$ \\
\hline $\begin{array}{l}\mathrm{L} \\
\mathrm{H}\end{array}$ & $\begin{array}{l}.222^{*} \\
.078^{*}\end{array}$ & $\begin{array}{l}.627 * \\
.910^{*}\end{array}$ & $\begin{array}{l}.222 * \\
.078 *\end{array}$ & $\begin{array}{l}.627^{*} \\
.910^{*}\end{array}$ & $\begin{array}{l}\text { Subject } \\
.219^{*} \\
.078^{*}\end{array}$ & $\begin{array}{l}.627^{*} \\
.910^{*}\end{array}$ & $\begin{array}{l}.219^{*} \\
.078^{*}\end{array}$ & $\begin{array}{l}.627^{*} \\
.910^{*}\end{array}$ & $\begin{array}{l}.010 \\
.034\end{array}$ & $\begin{array}{l}.092 \\
.675\end{array}$ \\
\hline \multicolumn{11}{|c|}{ Subject 6} \\
\hline $\begin{array}{l}\mathrm{L} \\
\mathrm{H}\end{array}$ & $\begin{array}{l}1 \\
.997\end{array}$ & $\begin{array}{l}1 \\
1\end{array}$ & $\begin{array}{l}.507 \\
.137^{*}\end{array}$ & $\begin{array}{l}.788 \\
.837 *\end{array}$ & $\begin{array}{l}.204 \\
.137^{*}\end{array}$ & $\begin{array}{l}.628 \\
.837^{*}\end{array}$ & $\begin{array}{l}.105 \\
.137^{*}\end{array}$ & $\begin{array}{l}.350 \\
.837^{*}\end{array}$ & $\begin{array}{l}.000 \\
.000^{*}\end{array}$ & $\begin{array}{l}.003 \\
.000^{*}\end{array}$ \\
\hline
\end{tabular}

*At least one response was never used. 
suit the experimenter's purposes. For an instructive example, see Ingleby (1969) and compare the account in Broadbent (1971).

\section{Isobias Data}

The isobias data from Experiments 1 and 2 appear in Figures 1 and 2, and those from Experiment 3 in Figure 3. Note that in all figures, the horizontal axis is $q$, the vertical $p$, and both are scaled in linear units from 0 to 1.) It can be seen by inspection that the plots are of quite different shape for different subjects. Measures $1^{*}$ to $4^{*}$ predict linear isobias functions: Some of the plots are approximately linear (e.g., Subject 1 in Experiment 1, Subject 1 in Experiment 2, and Subjects 3, 4, and 5 in Experiment 3), but others clearly are not linear (the best examples are Subjects 1, 2, and 6 in Experiment 3). Measures $5^{*}$ to $7^{*}$ predict curvilinear plots which, as discriminability increases, should go towards the top left corner of the square: Some of the plots are compatible with this prediction (e.g., Subject 4 in Experiment 1 and Subjects 1, 2, and 6 in Experiment 3), but others clearly are not (e.g., Subjects 1, 2, and 3 in Experiment 1, and Subject 2 in Experiment 2). The plots that go against
Measures $5^{*}$ to $7^{*}$ do so in different ways. Subjects 1 and 3 in Experiment 1 and Subject 2 in Experiment 2 show roughly linear plots with large positive slope; Measures $5^{*}$ to $7^{*}$ are compatible with positive slope only locally, in one part of the region to the left of the negative diagonal, where discriminability is low and bias is in favor of $r_{1}(\mathrm{No})$, and these conditions are not met here. Subject 2 in Experiment 1 , on the other hand, gives a plot that veers downwards towards the left-hand axis as discriminability increases, not upwards towards the top left-hand corner of the square. Altogether, it is quite clear by inspection that no one function from among Measures $1^{*}$ to $7^{*}$ can possibly fit more than a proportion of the data.

Subject 2 in Experiment 1 is an interesting special case, in that her plot is qualitatively incompatible with all of the proposals: None of them allows both $p$ and $q$ to decrease as discriminability increases, even locally, within the area to the left of the negative diagonal. Subject 3 in Experiment 1 also shows $p$ and $q$ decreasing, but within the area to the right of the negative diagonal: This is qualitatively (though not, perhaps, quantitatively) compatible with Measures $5^{*}$ to $7^{*}$, given that discriminability is low.
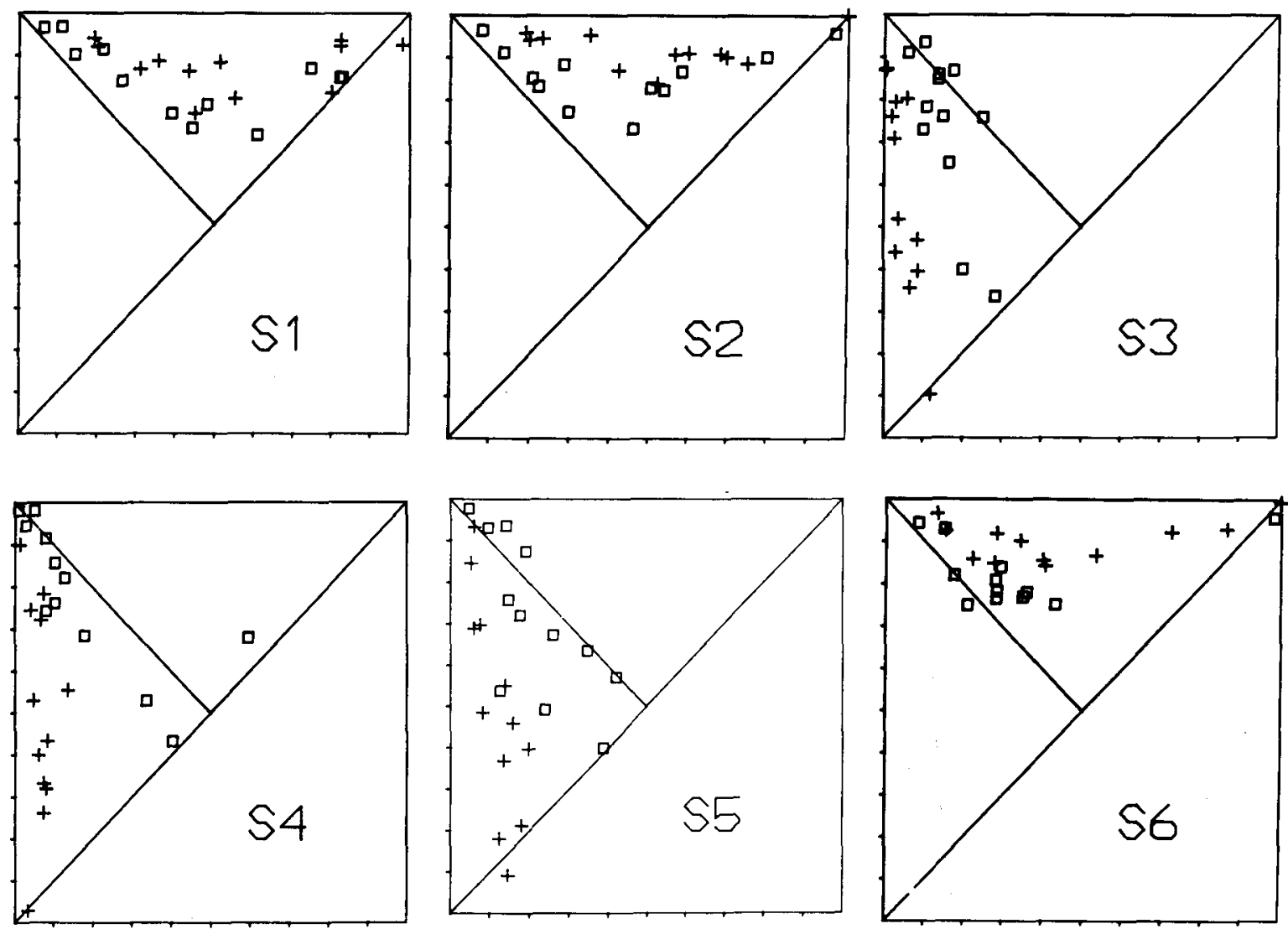

Figure 3. Isobias plots for Experiment 3. Vertical axis is p, horizontal is $q$; both axes are 0 to 1 linearly scaled. + , isobias/ $S Y M, \gamma \neq .5$; and $\square$, isobias/ASYM, $\gamma=.5$. There are 400 trials per point. 
In order to summarize the data further, it helps to give Kendall $\tau$ correlations between the various bias measures and $S / N$ ratio $\left(E / N_{0}\right)$. The main point of this is to show up some strong monotonic trends that are not immediately obvious to the eye, as instanced below. It should be noted most carefully that the correlation coefficients are capturing monotonic trend only: A negligible $\tau$ is quite compatible with appalling fit, either in the sense that residuals are large, or in the sense that there is a systematic, but nonmonotonic relation. Indeed, since the measures are themselves not monotonically related, it is impossible for all to correlate strongly with discriminability, even if all are inappropriate. For this reason, Table 2, which gives the $\tau$ correlations, needs to be interpreted in conjunction with the raw data plots of Figures 1, 2, and 3. It should also be noted that $\tau$ has to be used in a descriptive, rather than a significance-testing, spirit, since the usual null hypothesis for $\tau$ would make unwarranted assumptions about the variability of the hit and falsealarm estimates. Table 2 is especially useful with respect to the curvilinear functions, for which even a quite strong monotonic trend is difficult to spot unaided: See, for example, Subject 4 in Experiment 1 , and S1/ASYM, S2/SYM, S3/SYM, S5/ SYM in Experiment 3, for which $[\beta]$ looks promising in the figures but turns out to be implausible when we look at $\tau$. Of the linear isobias families, [q] fares badly throughout Table 2 , but [CER] and $\left[p\left(r_{2}\right)\right]$ do rather better. Unfortunately, this is in some cases a result of fitting a linear curve to clearly nonlinear data: See Subjects 1, 2, and 6 in Experiment 3, in both conditions, and note especially the zero discriminability points for Subjects 2 and 6 .

Table 2 also gives $\tau$ correlations between $\mathrm{d}^{\prime}$ and $\mathrm{S} / \mathrm{N}$ ratio. These are all close to 1 in Experiment 3, but not in Experiments 1 and 2. It must be remembered, however, that even binomial variability in the hit and false-alarm rate estimates would create a substantial variability in the estimates of $d^{\prime}$, and binomial variability is usually thought to be a gross underestimate of actual variability (Green \& Swets, 1966). Note also that $S / N$ levels were chosen informally on the basis of practice trials, and it is difficult to achieve an effective spacing of levels in this way, just because the closeness of the isosensitivity curves for $d^{\prime}$ varies greatly in different regions of the unit square. It is not surprising, therefore, that some of the subjects show only a moderately high correlation between $\hat{d}^{\prime}$ and $\mathbf{S} / \mathrm{N}$ ratio. The cautious reader may note, however, that these subjects could be put on one side without affecting the main conclusions of this study.

Taken together, then, Table 2 and Figures 1, 2, and 3 support the following remarks: (1) Each of

Table 2

Kendall $\tau$ Correlations Between E/ $\mathbf{N}_{0}$ and Parameter Estimates in Experiments 1, 2, and 3

\begin{tabular}{|c|c|c|c|c|c|c|c|c|}
\hline Subject & $\mathrm{d}^{\prime}$ & $\mathrm{q}$ & CER & $\mathrm{p}\left(\mathrm{I}_{2}\right)$ & $\mathbf{H}$ & $\log \beta$ & $\mathrm{C}$ & $\Phi^{-1}(\mathrm{p}) / \Phi^{-1}(q)$ \\
\hline \multicolumn{9}{|c|}{ Experiment 1} \\
\hline $\begin{array}{l}1 \\
2 \\
3 \\
4 \\
3 \mathrm{Y}\end{array}$ & $\begin{array}{l}.86 \\
.79 \\
.64 \\
.86 \\
.64\end{array}$ & $\begin{array}{r}.69 \\
-.86 \\
.93 \\
-.79 \\
.64\end{array}$ & $\begin{array}{r}-.93 \\
.79 \\
-.93 \\
.79 \\
-.79\end{array}$ & $\begin{array}{r}1 \\
\quad .86 \\
1 \\
-.79 \\
.79\end{array}$ & $\begin{array}{l}.43^{*} \\
.86 \\
-.29^{*} \\
.93 \\
.21^{*}\end{array}$ & $\begin{array}{r}.93 \\
-.86 \\
.79 \\
.57 \\
.71\end{array}$ & $\begin{array}{r}.93 \\
-.86 \\
1 \\
-.79 \\
.79\end{array}$ & $\begin{array}{c}-.93 \\
.86 \\
-1 \\
.93 \\
-.64\end{array}$ \\
\hline \multicolumn{9}{|c|}{ Experiment 2} \\
\hline $\begin{array}{l}1 \\
2 \\
3 \\
4\end{array}$ & $\begin{array}{l}.72 \\
1 \\
.93 \\
.93\end{array}$ & $\begin{array}{l}-.93 \\
-.29 * \\
-.71 \\
-.57\end{array}$ & $\begin{array}{l}-.26 * \\
-.64 \\
.57 \\
-.07 *\end{array}$ & $\begin{array}{c}-.79 \\
.50 \\
-.14 * \\
-.29 *\end{array}$ & $\begin{array}{l}.86 \\
.71 \\
.93 \\
.64\end{array}$ & $\begin{array}{c}.44^{*} \\
.64 \\
-.93 \\
.29 *\end{array}$ & $\begin{array}{l}-.29 * \\
.57 \\
-.21^{*} \\
-.07^{*}\end{array}$ & $\begin{array}{l}.07 * \\
-.50 \\
-.36^{*} \\
-.57\end{array}$ \\
\hline \multicolumn{9}{|c|}{ Experiment 3: Asymmetric Payoff } \\
\hline $\begin{array}{l}1 \\
2 \\
3 \\
4 \\
5 \\
6\end{array}$ & $\begin{array}{l}.97 \\
.97 \\
.91 \\
1 \\
1 \\
.91\end{array}$ & $\begin{array}{l}-.91 \\
-.82 \\
-.64 \\
-.87 \\
-.73 \\
-.81\end{array}$ & $\begin{array}{r}.24^{*} \\
.42^{*} \\
-.45^{*} \\
.03^{*} \\
-.33^{*} \\
.18^{*}\end{array}$ & $\begin{array}{c}-.85 \\
-.75 \\
.49^{*} \\
.38^{*} \\
.36^{*} \\
-.48^{*}\end{array}$ & $\begin{array}{l}.91 \\
.85 \\
.76 \\
.91 \\
.91 \\
.88\end{array}$ & $\begin{array}{r}.67 \\
.27^{*} \\
.18^{*} \\
-.24^{*} \\
.24^{*} \\
.30^{*}\end{array}$ & $\begin{array}{r}-.54 \\
-.48^{*} \\
.49^{*} \\
.18^{*} \\
.39^{*} \\
-.33^{*}\end{array}$ & $\begin{array}{l}-.12^{*} \\
.42^{*} \\
-.52 \\
-.76 \\
-.48^{*} \\
.18^{*}\end{array}$ \\
\hline \multicolumn{9}{|c|}{ Experiment 3: Symmetric Payoff } \\
\hline $\begin{array}{l}1 \\
2 \\
3 \\
4 \\
5 \\
6\end{array}$ & $\begin{array}{l}.97 \\
.94 \\
.94 \\
1 \\
1 \\
1\end{array}$ & $\begin{array}{l}-.85 \\
-.88 \\
-.78 \\
-.26 * \\
-.67 \\
-.91\end{array}$ & $\begin{array}{r}.39^{*} \\
.35^{*} \\
.30^{*} \\
-.45^{*} \\
-.39^{*} \\
.48^{*}\end{array}$ & $\begin{array}{c}-.44^{*} \\
-.69 \\
.42^{*} \\
.67 \\
.50 \\
-.55\end{array}$ & $\begin{array}{l}.97 \\
.88 \\
.82 \\
.85 \\
.97 \\
.94\end{array}$ & $\begin{array}{c}.47^{*} \\
.58 \\
-.64 \\
-.52 \\
-.55 \\
.09^{*}\end{array}$ & $\begin{array}{c}-.64 \\
-.81 \\
.48 * \\
.70 \\
.79 \\
-.64\end{array}$ & $\begin{array}{l}-.09 * \\
-.21 * \\
-.76 \\
-.85 \\
-.94 \\
-.23 *\end{array}$ \\
\hline $\mathrm{T} \dagger$ & & 2 & 14 & 8 & 3 & 9 & 9 & 9 \\
\hline
\end{tabular}

$\| \tau \mid<.5$. $\dagger$ Number of $|\tau|<.5$. 
the proposals fails for at least half the cases. Two ([q], [H]) fail almost universally. (2) Subjects do not always conform to $\left[\mathrm{p}\left(\mathrm{r}_{2}\right)\right]$, and they do not consistently undermatch $\left[\mathrm{p}\left(\mathrm{r}_{2}\right)<\gamma\right]$ or overmatch $\left[\mathrm{p}\left(\mathrm{r}_{2}\right)\right.$ $>\gamma$ ]: As argued in detail elsewhere (Dusoir, 1980), this shows that the only additive learning models that can fit all the data are those that are not actually tested by this kind of data, namely the general deterministic model and the general probabilistic model. (3) For two subjects (Experiment 1, Subjects 2 and 4 ), all the proposals fail.

It is worth noting that the failure of the isobias proposals is not just a consequence of chaotic data. Many of the plots are consistent in the sense that they would be quite well fitted by some fairly simple curve, at least in comparison with many published isosensitivity plots. The best examples are Subjects $1,2,3$, and 4 in Experiment 1, Subject 1 in Experiment 2 , and S1/ASYM, S3/SYM, S4/SYM, and S4/ASYM in Experiment 3. On the other hand, some plots would show very considerable variance whatever simple curve was fitted (e.g., S5/ASYM and S4/ASYM in Experiment 3).

Of course, it would be possible to redefine Measures $5^{*}, 6^{*}$, and $7^{*}$ relative to distributions other than the equal-variance normal ones assumed so far, though the isosensitivity plots impose some constraints. But it is very difficult to see how any such proposal could save any measure universally. Measure $6^{*}$, that is, $[\mathrm{C}]$, has to go towards the top left corner of the unit square $(q=0, p=1)$, and some of the plots do not do so: See Subjects 1, 2, and 3 in Experiment 1 . The curves of Measure $5^{*}$, that is, $[\beta]$, must join together points where the isosensitivity curves have equal slope, and this makes it impossible to fit cases like Experiment 1, Subjects 1, 2, and 3, and Experiment 2, Subjects 2 and 3 . In other cases, to introduce asymmetry by assuming, for example, exponential or unequalvariance normal distributions would actually make the fit of $[\beta]$ worse (Experiment 2, Subject 4; Experiment $3, \mathrm{~S} 1$ and $\mathrm{S} 2 / \mathrm{SYM})$. Asymmetry makes the curves for $\beta>1$ more strongly U-shaped, and makes them intersect the negative diagonal at high discriminability, whereas the problem with these subjects is that their plots are too shallow and/or stay too far away from the diagonal at high discriminability. Measure $7^{*}$, that is, Curry et al.'s (1977) proposal, is ruled out, at least as far as its original rationale and justification are concerned, by those subjects whose false-alarm rate varies between 0 and 1. The assumption of their model is that subjects keep a constant subjective false-alarm rate, and this is surely incompatible with an objective false-alarm rate varying between 0 and 1 , at least in a task with trial-by-trial feedback.

Post hoc, there is a way to make sense of Sub- jects 2 and 4 in Experiment 1, who both show hit rate and false-alarm rate decreasing with discriminability. Suppose that these subjects based their decisions on their estimates of the amount of energy around $1000 \mathrm{~Hz}$ that was present during the observation interval. Under the special conditions of Experiments 1 and 2, this amount must decrease as discriminability increases, since the amplitude of the noise burst decreases and signal strength stays constant. Suppose also that these two subjects responded "yes" $\left(r_{2}\right)$ only when the estimated amount of energy around $1000 \mathrm{~Hz}$ was greater than some constant that stayed fixed over all discriminability levels. On these assumptions, it is clear that both hit rate and false-alarm rate must then decrease with discriminability, as observed in these two subjects. Of course, this is speculation, but an interesting speculation, since it suggests a deep qualitative difference between subjects in what they are trying to do.

It is interesting, especially in connection with these two problematic subjects, to look again at the isosensitivity data of Experiments 1 and 2: Do the five 3-point isobias plots traced out by each subject in the isosensitivity conditions agree in shape with the plots traced out in the isobias conditions proper? In fact, both Subject 2 and Subject 4 in Experiment 1 show the same curious tendency to decrease hit rate as well as false-alarm rate as discriminability increases, in the isosensitivity data also, though the tendency is more systematic in Subject 2. Also, Subjects 1 and 3 show the same nearly vertical plots in both conditions. Other subjects' results are more equivocal, but there are no cases in which different curves would very clearly be needed in the two conditions, although it would be quite wrong to draw strong conclusions on such limited data.

\section{DISCUSSION}

As pointed out in the earlier paper (Dusoir, 1975), there seems to have been a widespread presumption that some uniquely and generally adequate bias measure must exist, the only problem being to find it. The results of this paper go against this presumption: At least within the experimental context used here, subjects appear to behave quite differently from one another as task difficulty is varied. Of course, it is possible that greater conformity could be found in some other experimental context, one in which discriminability was varied other than by $\mathrm{S} / \mathrm{N}$ ratio, perhaps, or one in which special training procedures were used. McCarthy and Davison (1981) have made one interesting proposal of this kind. Clearly, failure to find conveniently simple isobias behavior in one context should not be taken 
to imply failure in all possible contexts. Until a great deal of experimental work has been done, however, it seems unwise to presume identical isobias functions across subjects, and it becomes important to make clear the implications of this for use of the so-called bias measures.

One response to the idea that "we do not have an adequate bias measure" is to take a set of possible bias measures (for example, $1^{*}-7^{*}$ and to show that, whichever measure is used, two groups of points do or do not differ as to mean or median bias; see, for example, Wood (1976). This would be valid if we knew that one (unknown) member of the set of measures was appropriate for all subjects, but we do not know this, and so the argument is invalid. What else then is possible?

One idea worth making more precise is that two isobias curves might be validly compared even if they were from two different families, provided the two curves did not cross. Norman's (1964) nonparametric approach to discriminability is useful in refining this idea. Assume that isosensitivity curves have nonincreasing slope. Then, following Norman, for any point $\left(q^{\prime}, p^{\prime}\right)$, we can draw lines through $\left(q^{\prime}, p^{\prime}\right)$ from $(0,0)$ to the top axis, and from $(1,1)$ to the left-hand axis, dividing the unit square into four regions: the upper left one corresponds to certainly greater discriminability, the bottom right one corresponds to certainly lower discriminability, and the other two, $L\left(q^{\prime}, p^{\prime}\right) \subset I \times I, R\left(q^{\prime}, p^{\prime}\right) \subset i \times i$, where $I$ is the unit interval, satisfy

$$
\begin{aligned}
& q>q^{\prime}, p>p^{\prime} \text { for all }(q, p) \varepsilon R\left(q^{\prime}, p^{\prime}\right) \\
& q^{\prime}<q^{\prime}, p<p^{\prime} \text { for all }(q, p) \varepsilon L\left(q^{\prime}, p^{\prime}\right)
\end{aligned}
$$

and together contain the whole of the isosensitivity curve through $\left(q^{\prime}, p^{\prime}\right)$. Suppose $B_{1} \subset I \times I, B_{2} \subset I \times I$ are two isobias curves. If, and only if, $B_{2}$ lies wholly to the right of $B_{1}$, in the special sense

$$
B_{2} \subset \underset{(q, p) B_{1}}{\cup} R(q, p)
$$

then in view of Equation 1 we can say that $B_{2}$ shows greater bias to $r_{2}$ than does $B_{1}$, and the converse if, and only if,

$$
B_{2} \subset \underset{(q, p) B_{1}}{\cup} L(q, p) \text {. }
$$

Note that this definition makes parts of isobias curves comparable sometimes, unlike a simpler definition in terms of noncrossing, which must be restricted to whole curves. $\mathrm{B}_{1}, \mathrm{~B}_{\mathbf{2}}$ here are theoretical curves, of course, not empirical isobias plots, and inference from the latter to the former has to be cautious without some explicit and confirmed theory of variance in the unit square.

The above defines a sense in which isobias curves may be comparable even when they come from quite different curve families. It is important to note that two points may be ordered as to bias only when they lie on comparable isobias curves in this sense. This is easy to overlook: There is, of course, a restricted sense in which, if they do not differ in sensitivity, two distinct points must "differ in bias; they do not lie on the same isobias curve. But we cannot, in general, go on to say that one shows greater bias to $r_{2}$ than the other, unless we explicitly restrict this claim to the particular level of discriminability involved, since elsewhere the parent isobias curves may cross and reverse the order. In short, it is difficult to make any valid inferences at all about bias without troubling to trace out reasonably full isobias plots with each subject.

It should be noted that even if no valid bias measures were ever found, this would in no way go against the use of those discriminability measures, such as d', that are solidly based on the shape of empirical isosensitivity plots. This, at least, is reassuring. It would be quite wrong, however, to think of the bias issue as of minor importance. Many applications of signal detection models, for example, to recognition memory, turn out to make strong and possibly simplistic assumptions about bias. Also, it is worrying to think that in practical decision-making situations outside the laboratory, people may be handling bias in as nonoptimal a way as in the present context.

\section{REFERENCES}

Amble R, S. A simple learning model for signal detection tasks. British Journal of Mathematical and Statistical Psychology, 1976, 29, 157-174.

Broadbent, D. E. Decision and stress. London: Academic Press, 1971.

Craig, A. Signal recognition and the probability-matching decision rule. Perception \& Psychophysics, 1976, 20, 157-162.

Curny, R. E., NaGel, D. C., \& GaI, E. G. Decision behavior with changing signal strength. Journal of Mathematical Psychology, 1977, 15, 46-69.

Dusolr, A. E. Treatments of bias in detection and recognition models: A review. Perception \& Psychophysics, 1975, 17, 167-178.

Dusolr, A. E. Some evidence on additive learning models. Perception \& Psychophysics, 1980, 27, 163-175.

EgAN, J. P. Signal detection theory and ROC analysis. New York: Academic Press, 1975.

Green, D. M., \& Swets, J. A. Signal detection theory and psychophysics. New York: Wiley, 1966.

Hardy, G. R., \& LegGe, D. Cross-modal induction of changes in sensory thresholds. Quarterly Journal of Experimental Psychology, 1968, 20, 20-29.

Healy, A. F., \& Jones, C. Criterion shifts in recall. Psychological Bulletin, 1973, 79, 335-340. 
Inghaм, J. B. Individual differences in signal detection. Acta Psychologica, 1970, 34, 39-50.

INGLEBY, J. D. Decision making processes in human perception and memory. PhD thesis, University of Cambridge, 1969.

Kornbrot, D. E., Donnelly, M. D., \& Galanter, E. Estimates of utility function parameters from signal detection experiments. Journal of Experimental Psychology: Human Perception and Performance, 1981, 7, 441-458.

LuCE, R. D. Detection and recognition. In R. D. Luce, R. R. Bush, \& E. Galanter (Eds.), Handbook of mathematical psychology (Vol. 1). New York: Wiley, 1963.

MCCARTHY, D., \& DAvison, M. Towards a behavioral theory of bias in signal detection. Perception \& Psychophysics, 1981, 29, 371-382.
Norman, D. A. A comparison of data obtained with different false-alarm rates. Psychological Review, 1964, 71, 243-246.

Treisman, M. The effect of one stimulus on the threshold for another: An application of signal detectability theory. British Journal of Statistical Psychology, 1964, 17, 15-35.

WooD, C. C. Discriminability, response bias, and phoneme categories in discrimination of voice onset time. Journal of the Acoustical Society of America, 1976, 60, 1381-1389.

(Manuscript received May 24, 1982; revision accepted for publication January 26, 1983.) 